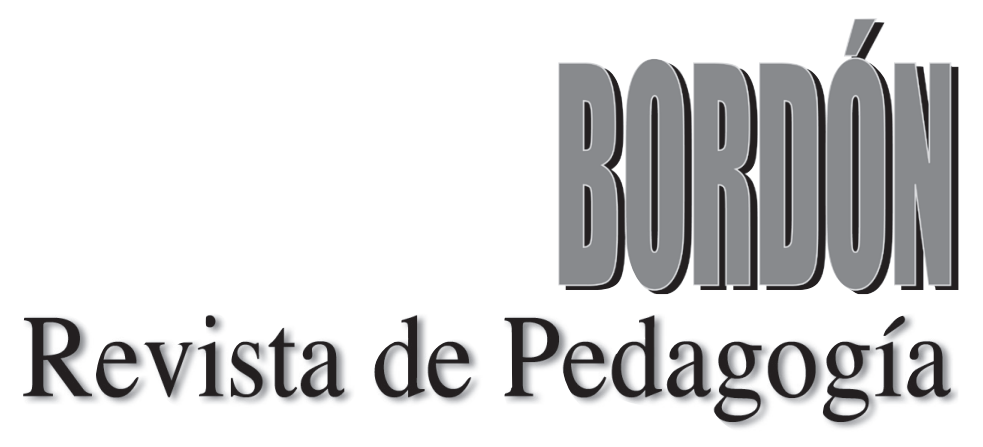

NÚMERO MONOGRÁFICO / SPECIAL ISSUE

Ética y universidad /
Ethics and university
Francisco Esteban y Pádraig Hogan
(editores invitados / guest editors)

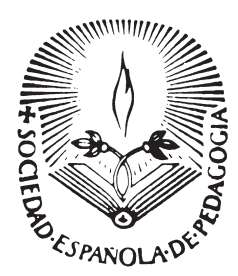

\author{
Volumen 69 \\ Número, 4 \\ 2017
}




\section{La apuesta por la literatura para la formación ética en la universidad. Una experiencia de aula con estudiantes colombianos}

\section{The commitment to literature for ethical training in the university. A classroom experience with Colombian students}

VICTORIA EUGENIA ÁNGEL ALZATE

Universidad Tecnológica de Pereira

D0I: 10.13042/Bordon.2017.690406

Fecha de recepción: 20/01/2017 - Fecha de aceptación: 19/05/2017

Autora de contacto / Corresponding Author:Victoria Eugenia Ángel Alzate. E-mail: vican@utp.edu.co

INTRODUCCIÓN. El presente artículo pretende evidenciar cómo la literatura se erige en una alternativa válida para trabajar los valores ciudadanos con los estudiantes de educación superior, haciendo posible la conexión de la razón con la emoción con el fin de superar el déficit motivacional de las éticas cognoscitivas, al que aluden reiteradamente los especialistas en filosofía moral. El análisis se lleva a cabo a partir de una experiencia de aula en el marco de un proyecto de investigación en una universidad colombiana. MÉTODO. La muestra la constituye un grupo de estudiantes de ambos sexos de quinto semestre de Tecnología Industrial de una universidad colombiana a quienes se les aplicó un cuestionario de pregunta abierta en dos momentos, antes y después de la lectura de una novela, con el fin de evaluar la incorporación de valores éticos y ciudadanos. RESULTADOS. Los resultados nos permiten verificar un cambio en los juicios de valor emitidos por los estudiantes habiéndose operado en esa misma dirección una transformación en sus imaginarios respecto de los fenómenos del narcotráfico, la corrupción y el conflicto armado colombiano. DISCUSIÓN. De la investigación en cuestión se derivan alcances significativos para la formación en valores éticos y ciudadanos en estudiantes universitarios y puede servir de base para futuras investigaciones en el campo pedagógico. La literatura demuestra ser un medio idóneo para conectar la razón con la emoción y contribuir a la superación del déficit motivacional en los estudiantes cuando se emprende su formación en valores éticos y ciudadanos y se busca, de otro lado, incentivar una conciencia histórica.

Palabras clave: Educación superior, Literatura, Sensibilización moral, Valores ciudadanos, Memoria histórica. 
El 2016 pasará a la historia como un año que nos dio mucho que pensar y no menos que sentir. Entre los hechos noticiosos que generaron mayor impacto se encuentran aquellos relacionados con actos de corrupción y de manipulación de la información, que en el caso de los Estados Unidos y Colombia tuvieron grandes repercusiones en sus respectivos procesos electorales. En el caso específico de estos dos países, la elección de Donald Trump y el triunfo del No en el Plebiscito por la Paz en Colombia, importantes analistas políticos han puesto en evidencia las flagrantes mentiras que circularon en periódicos y revistas, en la televisión y muy especialmente, en Internet, con particular énfasis en las redes sociales; un gran porcentaje de los votantes fue manipulado, no verificó si la información era ajustada a la realidad, o lo que es peor, no acudió a las urnas para ejercer su derecho al voto, dejando las decisiones cruciales para su país en manos de unos pocos. Pareciera que "hay cada vez más 'likes' en las redes, y cada vez menos votos en las urnas" (Rizzi, 2016); las cifras son elocuentes, en el caso colombiano el porcentaje de abstención fue el más alto en 22 años, 62,59\% de los colombianos habilitados no votó (El Tiempo, 2016).

Que ahora los medios de comunicación hablen de posverdad como un fenómeno propio de las redes sociales, no deja de ser paradójico, cuando antes las mismas habían sido objeto de elogio con motivo de la primavera árabe, y ahora se les atribuye, en cambio, la manipulación de la opinión pública, al punto de elegir presidentes y cambiar plebiscitos. En sus Diálogos de juventud, Platón había expuesto que quien está en capacidad de hacer el bien también lo está de hacer el mal. Lo que aplica, por supuesto en las redes sociales no menos que en los grandes medios de comunicación, quienes han demostrado en no pocos casos estar al servicio de las grandes corporaciones que financian sus pautas publicitarias.

Lejos de circunscribirse al mundo electoral, los antivalores como el engaño y la codicia, entre otros, constituyen un fenómeno de nuestro tiempo. Los grandes escándalos de corrupción llenan los titulares de prensa a diario, suscitan discusiones y son tema de conversación en reuniones sociales, pero no generan ninguna movilización ciudadana y rápidamente pasan al olvido, tal como lo confirma Beatriz Sarló (1996). En no pocos casos los implicados salen absueltos o pagan condenas irrisorias, y lo que es peor, no reciben ninguna sanción social.

Según cifras de Transparencia Internacional del año 2015, Colombia ocupa el puesto 83 entre 167 países en el índice de percepción de la corrupción (Transparency International, 2016). La mayor parte de los protagonistas de dichos escándalos son individuos educados en las mejores universidades, con posgrados, lo que entra en contradicción con la máxima socrática: "el hombre hace el mal por ignorancia" (Platón, 1966). Cabe preguntarnos entonces: ¿Qué está pasando con la educación?

En medio de la "objetividad" mercenaria de los medios y la subjetividad manipuladora de las redes, la construcción de ciudadanía remite a la educación. El déficit motivacional de las éticas cognoscitivas, no obstante, nos deja sin opciones. ¿Qué hacer? Es cuando se impone una revisión de nuestra antropología.

Aparte del alma racional, Platón había reconocido la existencia de un alma irascible, es decir, emocional, y un alma concupiscible, es decir, instintiva, compatible, en principio, con la idea del cerebro triuno (Mac Lean, 1978), que se impone en las neurociencias. Para este académico norteamericano, en el cerebro se superponen tres capas, a saber: el archicerebro o cerebro reptil, encargado de la supervivencia; el sistema límbico, responsable de las emociones, y el neocórtex, que hace posible el pensamiento racional. Aristóteles, no obstante, define al hombre como animal racional, fórmula que se repite generación tras generación, en la medida en que nos hace sentir diferentes, y en particular, superiores. Aristotélicos por defecto, hacemos 
de lo racional sinónimo de lo cerebral. Una persona racional se considera una persona cerebral o viceversa. Aunque el término ratio, en latín, proceda del logos griego, discurso, lenguaje, no son sinónimos ni mucho menos. Con el término razón, se dejan por fuera los usos retóricos del lenguaje, privilegiando, en cambio, la argumentación, cuando no el silogismo (Aristóteles). Que no solo confiemos en la razón para explicar ideas sino, además, para acreditar valores es un corolario del racionalismo en cuestión. Es cuando surgen las éticas cognoscitivas, entendidas como aquellas que se derivan del planteamiento kantiano (Kant, 1951) según el cual la comprensión de la ley moral nos obliga a su cumplimiento, cuyo más remoto antecedente nos conduce hasta Sócrates cuando afirma que nadie hace el mal sino por ignorancia; es cuando optamos por el estilo plano con el ánimo de expulsar la emoción de los dominios del discurso. Se deja de lado la concepción originaria de la filosofía como dinámica emociónrazón: philo, amor, amante; sophia, saber, en un camino engalanado de nombres ilustres como si de argumentos de autoridad se tratase. Con el reconocimiento del déficit motivacional de las éticas cognoscitivas, no obstante, se ha desmantelado la falacia. Habiendo llegado a un callejón sin salida, de vuelta a la concepción tripartita del alma expuesta por Platón, inevitable es fijar la atención en el único ámbito del discurso que se resistió a ser colonizado por el estilo plano: la literatura, en donde la dinámica emoción-razón es potenciada por la retórica como ocurría en los presocráticos, autores de versos (Parménides) y aforismos (Heráclito). Recuperar la dinámica emoción-razón como propone Martha Nussbaum en Justicia poética, en lo que insiste también Victoria Camps en El gobierno de las emociones (2011), sería una provocación que nosotros nos proponemos confirmar, en contravía con uno de los signos de nuestro tiempo en el que la racionalidad instrumental se pone al servicio del reptil.

Erigido el capitalismo en modo de ser por obra y gracia de la publicidad, cuando los antivalores que las religiones habían proscrito son rescatados, cuando el afán de lucro se define como medida de todas las cosas, cuando la política degenera en profesión, cuando se acuña el término "políticos de alquiler" (Serna, 2017), es menester rescatar la política de la economía, única vía disponible para reconciliarla con la ética, que se ocupa de valores diferentes al precio, en concordancia, en cambio, con la economía del don, con la concepción de "amistad sin reciprocidad", tal como lo propone Derrida (1999).

Tal como lo planteamos en el proyecto de investigación, reconocemos que a partir de la senda abierta por pensadores como Wittgenstein (1988) y Heidegger (1990), quienes constataron el poder que posee la palabra para gestar el mundo, como Bajtín (1982) que nos reveló que el lenguaje es ante todo una construcción social, y de Richard Rorty (1991), quien nos advierte de que lenguajes diferentes crean hombres diferentes, se hace evidente la necesidad de formular una ética acorde con estos tiempos de cambio, que sensibilice a los sujetos, como acontece con el arte, y especialmente con la literatura. Se hace imperativo habilitar nuevas formas de reconocernos, nuevas maneras de introducir la discusión acerca de lo que entendemos por una vida buena, hacernos la pregunta sobre los valores éticos que deben guiar nuestras acciones en el ámbito público y privado, sobre los modos de asumir la ciudadanía en el mundo contemporáneo, una ciudadanía planetaria (Nussbaum, 2001) que no soslaye, sin embargo, sus orígenes y sus especificidades.

Situados en este contexto, todos aquellos que nos dedicamos a la enseñanza ya no podemos ser más perpetuadores de modelos educativos desuetos; nuestra labor consiste en reorientar el proceso de formación y crear espacios de reflexión y sensibilización no solo para que los estudiantes ahonden en los interrogantes que les competen, sino, además, para construir nuevas formas de convivencia, donde nos reconozcamos y nos aceptemos en nuestras diferencias, para que se conviertan en verdaderos agentes de 
cambio y asuman responsablemente como sujetos políticos activos su papel en la construcción de la sociedad del porvenir. Para el logro de este propósito reconocemos en la literatura una gran aliada para conectar la razón con la emoción, para lograr la identificación con el otro, para asumir la tolerancia y la hospitalidad como formas de vida, para educar ciudadanos sensibles que transformen sus respectivas sociedades.

En el modelo de universidad tradicional, que se remonta al siglo XIX, la Facultad de Educación, la Facultad de Filosofía y el Departamento de Literatura suelen estar en edificios separados en el campus, lo cual se considera acorde con la estructura feudal de los saberes en la que las diversas disciplinas se constituyen en auténticos guetos. En contravía con esa concepción feudal del saber, los problemas contemporáneos en su inaudita complejidad reclaman una mirada transdisciplinaria, los saberes se superponen, fusionan y entrecruzan de manera rizomática y paradójica. Hay autores que han anticipado este cambio paradigmático, tal es el caso de Mijail Bajtín, en quien se imbrican la literatura, la filosofía y la lingüística; Borges y Piglia hacen lo propio con los géneros literarios.

Educación, filosofía y literatura, tres saberes distintos, tres facultades distintas; no sería la mejor alternativa. Filosofía sin literatura es momia conceptual (Nietzsche, 1967), educación sin filosofía es racionalidad instrumental, literatura sin filosofía puede degenerar en cultura light, por citar algunos ejemplos. Como alternativa proponemos trabajar en los cruces de la educación con la filosofía y la literatura. Si pensamos en la educación como filosofía aplicada nos encontramos con el déficit motivacional de las éticas cognoscitivas y es en ese contexto donde cobran vigencia las tesis de Martha Nussbaum relativas a la sensibilización moral a través de la literatura, tesis desarrollada por la autora en su obra Justicia poética:

"Es la emoción del espectador juicioso, la emoción que las obras literarias forjan en sus lectores, que aprenden lo que es sentir emoción no por 'una masa anónima e indiferenciada', sino por 'el ser humano individual y singular'. Ello significa que las obras literarias son lo que [Adam] Smith creía que eran: elaboraciones artificiales de ciertos elementos cruciales para una norma de racionalidad pública, y valiosas guías para una respuesta acertada" (Nussbaum, 1997: 114).

Si aceptamos con Martha Nussbaum la necesidad de replantear una ética más acorde con estos tiempos líquidos (Bauman, 2002, 2007, 2013), si admitimos la necesidad de habilitar otras formas de sensibilizar a los sujetos, como es el caso de la literatura, no podemos menos que asumir el estudio de los horizontes abiertos por esta disciplina en lo relativo a la construcción de un sujeto ético y político, capaz de adoptar la tolerancia, la alteridad y la hospitalidad como valores insustituibles en la construcción de una sociedad mejor. En este mismo sentido, Rorty en Filosofía y futuro (2002) trabaja la noción de solidaridad, para la cual es necesario cultivar la capacidad imaginativa de ver a los demás como compañeros en el sufrimiento:

"Porque ahora el problema político —el problema de lograr una cooperación social entre seres humanos- se convierte en un problema de tolerar fantasías alternativas y ya no de eliminar la fantasía en aras de la verdad. La cuestión no es cómo conseguir que los seres humanos vivan de acuerdo con la naturaleza, sino cómo conseguir que vivan en una misma comunidad con gente que tiene nociones distintas acerca del sentido de la vida humana" (Rorty, 2002).

Con la pérdida de protagonismo de la experiencia religiosa registrada en el último par de siglos, el fomento de los valores morales, de las normas de convivencia ciudadana y de los criterios éticos para un mejor vivir han perdido el más eficaz de sus sustentos representado por la esperanza de la bienaventuranza eterna. Han ocupado su lugar, en lo sucesivo, una serie de consideraciones tendientes a regular la relación 
del individuo con sus semejantes a partir de la argumentación, conocidas con el nombre genérico de éticas cognoscitivas, no obstante, el déficit motivacional que se les atribuye, en virtud de su dificultad manifiesta para traducirse en acción. Es entonces cuando propuestas como la formulada por Martha Nussbaum, en el sentido de utilizar las posibilidades abiertas por la literatura, y más exactamente por la imaginación literaria, en aras de conectar la razón con la emoción, adquieren una vigencia de primer orden. Como lo advierte la misma Nussbaum, si bien, cualquier género literario puede servir, en principio, para tal fin, es la novela el género por medio del cual damos cuenta de las expectativas y las vicisitudes a través de las cuales se forja la existencia, ya que: "La novela construye un paradigma de un estilo de razonamiento ético que es específico al contexto sin ser relativista, en el que obtenemos recetas concretas y potencialmente universales al presenciar una idea general de la realización humana en una situación concreta, a la que se nos invita a entrar mediante la imaginación" (Nussbaum, 1997: 33).

La idea de la educación repetitiva y reproductora estaría en consonancia con la clase magistral. En general, pudiéramos decir que las prácticas pedagógicas no son neutrales y que en última instancia están comprometidas con una determinada concepción de mundo. Mientras los cambios históricos fueron lentos o mientras la conciencia histórica fue leve, la clase magistral se erigía en la vía por excelencia del proceso educativo. Hoy el mundo es otro, avalanchas de información saturan los mass media. La crisis de los sistemas, el multiculturalismo también, han terminado por potenciar la evidencia del cambio a niveles sin precedentes. Progresivamente hace carrera la idea según la cual vivimos en un mundo mudable, cuando no desechable. El universalismo ha cedido su puesto a un contextualismo que hace carrera no solo en las diversas disciplinas humanísticas sino sobre todo en la cotidianidad, cuando no es que definitivamente optamos por el relativismo. Todo lo cual nos hace pensar en que la educación del siglo
XXI no puede seguirse adelantando a partir de los objetivos y los métodos que estaban en boga en el siglo XIX.

Acogemos las tesis de Rorty (1991) para quien son los literatos los encargados de abrir mundo a diferencia de los filósofos que se ocuparían de ordenarlo. En tiempos inciertos como los nuestros es evidente que la imaginación hace la diferencia y en esas circunstancias la educación no debe limitarse a la resolución de problemas, cuando además debe priorizar las aperturas de mundo. Nos interesa también la obra de Martha Nussbaum cuando reconoce las dificultades relativas a la motivación de la conducta moral experimentadas por las éticas cognoscitivas, cuando no solo encuentra en la novela una pedagogía de la diversidad, sino además la posibilidad de reconectar la razón con la emoción.

Tal como lo señala Louise Rosenblatt (2003), la literatura es un vehículo para reflexionar sobre los asuntos humanos, para experimentarlos en tiempo real, añadiríamos nosotros. En tal sentido, los integrantes del grupo de investigación Lenguaje, Literatura y Política: Estudios Transversales, adscrito a la Facultad de Educación de la Universidad Tecnológica de Pereira (Colombia), planteamos el proyecto de investigación "Educar en valores. Una apuesta desde la literatura" que se proponía identificar algunas novelas latinoamericanas que incorporadas al proceso educativo lograran sensibilizar moralmente a nuestros estudiantes y sirvieran al propósito de formación en valores ciudadanos; esto con el fin de emprender una propuesta pedagógica que se valga de las fortalezas de la literatura para implementarla en el ámbito educativo universitario. Que se narraran problemas sociales específicos, como la violencia, la desigualdad, el narcotráfico, la corrupción, entre otros, y que se pusieran en juego conflictos éticos, fue el criterio de selección de las novelas.

El objetivo general que se propuso fue identificar en la narrativa latinoamericana algunos ejemplos prototípicos que incorporados al 
proceso educativo en nuestro ejercicio docente contribuyan a la sensibilización moral y a la formación en valores ciudadanos.

Los objetivos específicos perseguidos por este proyecto fueron los siguientes:

1) Ahondar en las especificidades del ser latinoamericano a partir de las más representativas obras de filósofos y sociólogos contemporáneos relacionados con el tema.

2) Identificar los valores ciudadanos que se ponen en juego en las obras literarias seleccionadas.

3) Construir una propuesta pedagógica con el fin de aplicar en el ámbito educativo universitario los resultados de la investigación.

Se trató de una investigación cualitativa que se desarrolló a través de los siguientes momentos:

1) Lectura de teóricos como Adela Cortina (2009, 2013), Beatriz Sarló (1996), Néstor García Canclini (1989, 1995), Boaventura de Souza Santos (2009), Mijail Bajtín (1982), Richard Rorty (2005), Louise Rosenblatt (2003), George Lakoff y Mark Johnson (1995), entre otros, con el ánimo de precisar los retos para la convivencia en el mundo contemporáneo con énfasis en Latinoamérica.

2) Revisión y análisis de las obras literarias latinoamericanas que pudieran ofrecer interés en aras de promover los valores ciudadanos.

3) Evaluación en las obras elegidas de las estrategias escriturales utilizadas, estilo, figuras retóricas y demás recursos literarios en relación al sistema de valores sustentado por ellos.

4) Incorporación de los resultados de la investigación a la práctica docente en cursos y seminarios.

Algunas de las novelas seleccionadas fueron: Con sangre en el ojo de Lina Meruane, Los ejércitos de
Evelio Rosero, Últimas noticias del paraíso de Clara Sánchez, La luz difícil de Tomás González, El ruido de las cosas al caer de Juan Gabriel Vásquez, El mundo de afuera de Jorge Franco, Cartas cruzadas de Darío Jaramillo Agudelo, entre otras. A partir de los resultados obtenidos en la fase inicial del proyecto cada uno de los integrantes del grupo debía escoger una o varias novelas para trabajarlas con sus respectivos alumnos; el presente artículo recoge los resultados de uno de los cursos en los que se puso a prueba la propuesta de formación en valores. Esta se implementó en la asignatura de Constitución Política y Ética, la cual es de carácter obligatorio en todos los planteles educativos colombianos para todos los niveles de formación, según lo estipula el artículo 41 de la Constitución Política. En el caso de la Universidad Tecnológica de Pereira, dicha asignatura está incorporada en los planes educativos de todas las facultades; sin embargo, su intensidad horaria varía y cada profesor tiene libertad para estructurarla y darle los énfasis que considere pertinente. Uno de los objetivos de dicha asignatura es la de propiciar en los estudiantes una conciencia acerca de los procesos históricos y políticos que ha atravesado el país y que en buena parte explican los acontecimientos en la actualidad. Con la convicción de que la novela representa un medio idóneo para recuperar la memoria histórica acogemos las no menos oportunas que precisas palabras de Joan-Carles Mèlich:

"La narración es portadora de sentido, no intenta resolver los problemas (al modo de los especialistas técnicos), sino provocar que el ser humano se enfrente a las cuestiones fundamentales de la existencia. Por la narración, el ser humano vive el pasado en el presente, comprende que el pasado sigue abierto, que no ha concluido. Por la narración, el ser humano es oyente de las voces excluidas de la historia" (Mélich, 2001: 56).

Para nadie es un secreto que el fenómeno del narcotráfico ha permeado todas las capas de la sociedad y las instituciones del Estado colombiano. 
Este flagelo ha dejado miles de muertos, lisiados, familias destruidas, ha alimentado la corrupción, ha contaminado la política hasta límites inimaginables, ha servido de combustible a la guerra interna; a pesar de todo lo negativo que ha traído consigo, en muchos casos ha sido naturalizado e incorporado de variada manera en el imaginario de muchos colombianos; a diario se transmiten novelas y series de televisión donde prácticamente se hace una apología del mundo narco. Ante esta problemática resulta indispensable formar sujetos críticos, que se atrevan a cuestionar y a transformar la realidad, a rescatar los valores que requieren nuestras sociedades; por todo lo anterior se eligió El ruido de las cosas al caer de Juan Gabriel Vásquez (2011) porque si bien es una novela en la cual se habla del narcotráfico, este se aborda de una manera crítica y se centra en tres momentos históricos asociados a este fenómeno. Esta obra se aparta de la "sicaresca" (Jácome, 2009), término irónico para referirse a aquellas novelas cuyos protagonistas forman parte del mundo del narcotráfico, y que en muchos casos han sido llevadas a la televisión y al cine con bastante éxito, incluso en el resto de Hispanoamérica.

Es importante anotar que la Universidad Tecnológica de Pereira, como su nombre lo indica, es una institución educativa donde los programas de ingenierías y tecnologías tienen mayor peso, así que no contamos con el compromiso previo de los estudiantes con los temas humanísticos y éticos en razón de su vocación y su trayectoria, por lo que se hace necesario implementar estrategias pedagógicas que acerquen y motiven el abordaje de estos temas. En segundo lugar, entre los jóvenes hay poco interés por los asuntos políticos, bien por desprecio de las prácticas corruptas a las que a diario hacen alusión los medios de comunicación, bien porque las redes sociales acaparan su tiempo, bien porque el individualismo y el materialismo, eje de coordenadas de nuestro tiempo, los sustrae de los asuntos de índole social, y no faltan académicos que hablan de un aplazamiento de la política (Carrasco y Guerra, 2014); este grupo de estudiantes no sería la excepción, ya que desde un primer momento manifestaron su desencanto y desconfianza frente a todo lo que representa la política. Por último, y no menos importante de anotar sería que al momento de realizar esta actividad académica, tenía lugar el proceso de negociación de paz de La Habana entre el Estado colombiano y el grupo guerrillero de las FARC, lo que generó una gran polarización de la ciudadanía, entre los que estaban a favor y los que se manifestaban en contra.

\section{Método}

Muestra

Se seleccionó a los estudiantes de Constitución Política yÉética, de quinto semestre de Tecnología Eléctrica de la Universidad Tecnológica de Pereira, en total 28 estudiantes, 16 hombres y 12 mujeres, cuyas edades oscilaban entre 19 y 23 años.

\section{Instrumentos}

Se elaboró un cuestionario de pregunta abierta, ya que lo que se buscaba era que los estudiantes expresaran libremente su punto de vista acerca de los tópicos propuestos. Este cuestionario fue aplicado en dos momentos diferentes; al inicio del semestre académico y al final de todo el proceso; esto con el fin de evidenciar si la lectura de la novela logró cambiar su percepción del narcotráfico, los acontecimientos históricos y políticos derivados de dicha problemática y los valores éticos puestos en juego. Las preguntas fueron las siguientes:

1) ¿Qué opinión tiene de la clase política colombiana?

2) ¿Usted cree que la droga se debe legalizar?

3) ¿Usted cree que los grupos paramilitares llenan el espacio dejado por el Estado colombiano? 
4) ¿Cómo cree que los extranjeros ven a Colombia?

5) Nombre cinco cosas que usted cambiaría de Colombia.

6) ¿Cuáles cree que son los valores que son más importantes para los jóvenes de hoy en día?

7) ¿Qué le hace falta a la educación en Colombia?

En la segunda ocasión que se aplicó el cuestionario se añadieron dos preguntas:

8) ¿Qué valores y antivalores se ponen en evidencia en la novela?

9) Después de leer la novela, ¿qué propone para que en Colombia no vuelvan a repetirse los acontecimientos narrados en ella?

\section{Procedimiento}

Al inicio del semestre académico se entregó el cuestionario a los estudiantes para que fuera contestado individualmente en el aula de clase. La finalidad del cuestionario inicial era la de establecer, a través de las respuestas de los estudiantes, cuál era su opinión sobre el tema de las drogas, el narco-paramilitarismo, la clase política y el Estado colombiano (preguntas 1-5). Las preguntas 6 y 7 indagaban por los valores que consideraban más importantes y su relación con la educación.

En un segundo momento, se pidió a los estudiantes que leyeran los capítulos 1, 2, 4, 7 y 8 de ¿Para qué sirve realmente la ética? (Cortina, 2013), cuya finalidad era la de hacer las veces de norma evaluante (Hamon, 1984), ya que es un texto que demuestra la importancia de asumir una actitud ética si queremos construir sociedades más justas e incluyentes. En un tercer momento, se pidió a los estudiantes que leyeran la novela El ruido de las cosas al caer, se hizo una discusión colectiva acerca de esta, colocando especial énfasis en los tres acontecimientos históricos allí relatados, y, a través de sus opiniones, evaluar su discurso, y determinar cuáles eran sus expresiones disfóricas y eufóricas sobre los temas tratados; todo esto se recogió en una relatoría. En cuarto lugar, se solicitó a los estudiantes que volvieran a contestar el cuestionario al que se le añadieron dos nuevas preguntas, con el fin de comparar si se había producido un cambio en su valoración ética y en su opinión sobre los fenómenos asociados con el narcotráfico y los grupos paramilitares. La pregunta 8 iba encaminada a evidenciar el tipo de valores y antivalores puestos en juego por los personajes (Jouve, 2001) y cómo se situaban los estudiantes frente al discurso de la novela; el propósito de la pregunta 9 era suscitar no tanto una opinión, sino más bien una actitud propositiva por parte de los estudiantes. Finalmente, se solicitó que entregaran un trabajo con sus reflexiones sobre la actividad realizada en relación con la situación actual de Colombia.

Se procedió a hacer un análisis comparativo de los documentos producidos por cada estudiante, a saber, los dos cuestionarios de pregunta abierta, la relatoría y el trabajo final, desde la perspectiva del análisis del discurso (Van Dijk, 2013). Si aceptamos que hay una materialidad de los signos (Verón, 1998), es decir, que los discursos producen determinados efectos en la realidad social, es evidente que dichos discursos que circulan permanentemente en la cotidianidad y a través de los medios de comunicación, y que en muchos casos no se ajustan a la legalidad, se van incorporando en el imaginario de los individuos, y en este caso, en los estudiantes, lo que lleva en muchos casos a la naturalización de algunas conductas que entran en colisión con los valores trasmitidos y defendidos por la Constitución y las leyes. La pretensión de este proyecto era determinar si efectivamente se operaba un cambio entre la valoración ética de los fenómenos asociados con el narcotráfico y el conflicto armado en Colombia antes y después de leer la novela.

\section{Resultados}

En las respuestas al primer cuestionario encontramos los siguientes resultados: 
- Respecto de la primera pregunta llama la atención que en el $100 \%$ de respuestas tanto en hombres como mujeres hay una valoración negativa de la clase política; las palabras más usadas en sus argumentos son la corrupción y el individualismo.

- En lo que tiene que ver con el tema de la legalización de las drogas encontramos diferencias en las valoraciones éticas entre las mujeres y los hombres; hubo un mayor porcentaje de valoraciones negativas respecto de la legalización de las drogas entre las mujeres (80\%) respecto de los hombres (50\%).

- En cuanto a la tercera pregunta solo el $25 \%$ de los estudiantes consideró que los paramilitares han llenado el espacio dejado por el Estado.

- En la pregunta relativa a la manera cómo creen que nos ven los extranjeros, el $100 \%$ de los estudiantes piensa que los colombianos somos vistos como delincuentes y que se asocia nuestro país con la violencia y el narcotráfico, a pesar del relativo éxito que tenemos a nivel deportivo y artístico.

- La quinta pregunta, acerca de las cosas que cambiarían de Colombia, los resultados arrojan que el 70\% de los estudiantes ve el sistema educativo como un problema a resolver, seguido del sistema de salud (50\%), el sistema político y el gobierno (41\%), la corrupción (30\%), la desigualdad (22\%), distribución de tierras (15\%) y en ningún momento se hace alusión al narcotráfico.

- Respecto de la pregunta acerca de los valores que consideraban más importantes para los jóvenes de hoy, el 75\% contestó que consideraban el respeto como el más importante, seguido por la responsabilidad (40\%), la solidaridad (30\%), la tolerancia y la honestidad (26\%) y el compromiso (19\%); unos pocos mencionan la justicia, la lealtad, la autonomía, la rebeldía, la perseverancia, la humildad y la sinceridad, como valores importantes.
- Como era de esperarse por los resultados de la quinta pregunta la valoración sobre el sistema educativo colombiano es bastante negativo, aducen la falta de cobertura y de una buena remuneración a los maestros, una mejor calidad, falta de apoyo a las instituciones de educación pública, entre otros comentarios.

El segundo cuestionario mostró variaciones significativas respecto del cuestionario inicial en la respuesta a algunas preguntas y en otros casos se conservaron los resultados:

- Las respuestas a las preguntas 1, 2, 4 y 7 fueron prácticamente las mismas.

- Hubo variaciones respecto de la pregunta 3 , ya que a partir de la discusión sobre la novela se generó un cambio en la visión sobre el narco-paramilitarismo, la forma como este permeó todas las capas de la sociedad colombiana y las consecuencias en el ámbito político y jurídico del país.

- En las respuestas a las preguntas 5 y 6 , fue en donde se evidenciaron mayores cambios; en cuanto a la pregunta 5, si bien la educación se mantuvo como el mayor problema a resolver (60\%), la corrupción elevó su porcentaje al 40\% y aparece el narcotráfico en tercer lugar (38\%), seguido de la salud, el gobierno, la distribución de tierras y el manejo de los recursos naturales.

- La honestidad en la pregunta 6 fue el valor más mencionado, pasó del 26\% al $70 \%$ y la tolerancia pasó del $26 \%$ al $50 \%$, la responsabilidad y la solidaridad mantuvieron unos porcentajes cercanos a los del primer cuestionario.

- Como lo expresamos anteriormente, se añadieron dos preguntas más al cuestionario. En la pregunta 8 que indagaba sobre los valores y antivalores representados en la novela las respuestas fueron las siguientes: la solidaridad es el valor más importante (88\%), seguido por 
la sinceridad (40\%) y el compromiso (40\%). Se mencionan otros valores como la tolerancia, el respeto, la responsabilidad, la lealtad, la sencillez, pero no representan un porcentaje significativo de las respuestas. Cuando se pasa a hablar de los antivalores, la corrupción obtiene un $36 \%$, solo superado por la arrogancia y la infidelidad, ambos con un $60 \%$. Se mencionan otros antivalores como el irrespeto, la irresponsabilidad, la indiscreción y la codicia.

- A partir de las respuestas es importante analizar los valores y antivalores elegidos por los estudiantes, ya que esto dice mucho de sus imaginarios y de alguna manera son un reflejo de sus sentimientos morales; por qué le dan más importancia a unos valores que a otros o cuáles consideran que son las conductas que ameritan una mayor censura. Cabe señalar que se dieron algunas variaciones en las respuestas entre los hombres y las mujeres; los hombres le dan mayor importancia a la solidaridad (100\%) que las mujeres; por el contrario, entre las mujeres el valor más señalado fue el de la sinceridad (60\%). En cuanto a los antivalores, entre los hombres la arrogancia tuvo un mayor peso (75\%), mientras que la infidelidad fue el más reiterado en las mujeres (70\%).

- La pregunta 9 buscaba que los estudiantes asumieran una actitud propositiva para superar los problemas asociados al narcotráfico, la corrupción y el conflicto armado en Colombia, los que son evidenciados en la novela de Vásquez; $41 \%$ de los estudiantes argumentó que la solución a estos problemas requería hacer mayores esfuerzos en la educación, un $27 \%$ afirmó que se debía aprender de la historia y, por lo tanto, reclamaban mayor difusión de la información sobre estos temas con el fin de sensibilizar a la población, un $18 \%$ propuso como solución generar más cultura ciudadana, mientras el 14\% argumentó que era necesario un cambio en la mentalidad, y un mismo porcentaje pidió replantear los valores de la sociedad, el 9\% propuso eliminar la corrupción y crear más entes y mecanismos de control. Es llamativo que dos de los estudiantes manifestaron una total impotencia y no señalaron ninguna solución a los problemas que afectan a la sociedad colombiana, y solo uno propuso la legalización de las drogas.

Posteriormente se emprendió el análisis de la relatoría que se hizo de la discusión colectiva acerca de la novela. De las intervenciones de los estudiantes pudimos colegir que un número significativo de estudiantes (90\%) desconocía por completo los hechos narrados en la novela y que su apreciación sobre los orígenes del narcotráfico y su relación con el surgimiento de los grupos armados ilegales en Colombia era bastante superficial. Un hecho llamativo lo constituye la verificación de que sus opiniones en la mayoría de los casos (85\%), se apoyaron en los contenidos de las telenovelas y seriados; es decir, estos jóvenes aceptaban como argumento de autoridad los relatos ficcionales sobre narcotraficantes y sicarios, sin beneficio de inventario. Sin embargo, los juicios de valor expresados, sus expresiones disfóricas y eufóricas sobre los temas tratados nos permitió colegir que se había dado una transformación en sus imaginarios acerca del narcotráfico, la corrupción, sus protagonistas y el impacto en la sociedad colombiana, y que habían incorporado en su léxico algunos conceptos manejados por Adela Cortina en su libro, como el de cuidado, solidaridad, sociedad civil, responsabilidad, deterioro moral, entre otros.

Del análisis que se hizo de los trabajos finales pudimos verificar una mayor solidez en los argumentos, al tiempo que se generó un interés por profundizar en los temas tratados, se percibió una preocupación por indagar en los hechos históricos, así como la conquista de una mayor conciencia histórica, en la medida en 
que se estableció el vínculo causal entre los hechos del pasado y los acontecimientos del presente en nuestro país. Por último, los estudiantes calificaron como una necesidad para el mundo de hoy los valores éticos y morales; algunos, inclusive, se ocuparon de la ética profesional y la responsabilidad social en el desempeño laboral, la búsqueda del bien común sobre intereses particulares, y otros más se atrevieron a realizar una crítica de algunos sucesos noticiosos que consideraban antiéticos. Al final del semestre, seis estudiantes se inscribieron en un curso para veedurías ciudadanas ofrecido por el Concejo Municipal de Pereira, Colombia; estas tienen como propósito formar a las personas y a las organizaciones comunitarias para que ejerzan la labor de vigilancia sobre las entidades públicas y privadas y para que contribuyan al proceso de renovación de las costumbres y las prácticas ciudadanas. Todo lo cual demuestra que a través de la lectura de una novela que narra hechos controvertidos para la sociedad colombiana, como sería el caso del narcotráfico, se abrió un espacio de reflexión en el que un número considerable de los estudiantes ganó en términos de sensibilidad moral, lo cual demuestra, a nuestro juicio, la validez de la hipótesis inicial.

\section{Discusión y conclusiones}

Con la reivindicación de la emoción por las neurociencias, ha quedado en entredicho la autosuficiencia de la razón en el campo moral, uno de cuyos corolarios sería el consabido déficit motivacional de las éticas cognoscitivas. Todo lo cual haría necesario vincular la razón con la emoción como una manera de sensibilizar al estudiante en lo relativo a la moral. Y es justamente en este punto en el que se cifra la pertinencia de la literatura y muy especialmente la novela.

Fue así como en esta investigación, realizada con una muestra de estudiantes universitarios colombianos de quinto semestre de Tecnología
Eléctrica que cursaban la asignatura de Constitución Política y Ética, pudimos observar un cambio significativo en sus juicios de valor, al tiempo que se operó una transformación en sus imaginarios respecto de los fenómenos del narcotráfico, la corrupción y el conflicto armado, a partir de la lectura de una novela que aborda acontecimientos de la historia colombiana.

Cabe anotar que no se dieron diferencias significativas en las respuestas entre los grupos de mujeres y de hombres, aunque pudimos observar que hubo una menor coincidencia de opinión frente al tema de la legalización de las drogas. Hubo dos puntos en los cuales se dio un total consenso, en la desaprobación a la clase política y en la convicción de que hay una visión negativa sobre Colombia en el extranjero. Una amplia mayoría califica muy críticamente el sistema educativo y lo considera como el primer problema a resolver, por encima de la corrupción y el narcotráfico. El respeto es el valor más importante señalado por los estudiantes.

Un aspecto a destacar es el hecho de que buena parte de los participantes tenían poco o nulo conocimiento sobre los orígenes del narcotráfico y del conflicto armado. A partir de la lectura de la novela propuesta, se evidenció la importancia de indagar el pasado y recuperar la memoria histórica; esto se hizo palpable en las respuestas del segundo cuestionario y en el trabajo final. En la valoración total de la actividad los estudiantes manifestaron que la lectura de la novela logró que se interesaran por conocer la historia del país, lo que también se constató en las reflexiones del trabajo final. Resultó gratificante el hecho de que seis estudiantes se inscribieran en un curso de capacitación para veedores ciudadanos ofrecido por el Concejo Municipal de Pereira, ya que esto superó los objetivos planteados en el proyecto de investigación.

En conclusión, de los datos obtenidos en esta investigación se derivan resultados significativos para la formación en valores éticos y ciudadanos en estudiantes universitarios y puede 
servir de base para otras investigaciones en el campo pedagógico. La literatura demuestra ser un medio idóneo para conectar la razón con la emoción y contribuir a la superación del déficit motivacional en los estudiantes cuando se emprende su formación en valores éticos y ciudadanos y se busca incentivar una conciencia histórica.

\section{Referencias bibliográficas}

Bajtín, M. (1982). Estética de la creación verbal. México: Siglo XXI.

Bauman, Z. (2002). Modernidad líquida. México: FCE.

Bauman, Z. (2007). Tiempos líquidos. Barcelona: Tusquets.

Bauman, Z. (2013). Sobre la educación en un mundo líquido. Barcelona: Paidós.

Camps, V. (2011). El gobierno de las emociones. Barcelona: Herder.

Carrasco, D., Carrasco, J., y Guerra, E. (2014). Juventud y política en Antofagasta: Hacia una reinscripción de la experiencia política en jóvenes. Última Década, 22, 40, 85-107.

Cortina, A. (2009). Ciudadanos del mundo: Hacia una teoría de la ciudadanía. Madrid: Alianza.

Cortina, A. (2013). ¿Para qué sirve realmente la ética? Barcelona: Paidós.

De Souza Santos, B. (2009). Pensar el Estado y la sociedad: Desafíos actuales. Buenos Aires: Waldhuter.

Derrida, J. (1999). Un pensamiento amigo. "Derrida à prix de ami", entrevista con Robert Magiore, traducción de Rosario Ibáñez y María José Pozo. Liberation, 24 de noviembre de 1994. En J. Derrida, No escribo sin luz artificial, pp. I-III. Valladolid: Cuatro Ediciones. Recuperado en http:// personales.ciudad.com.ar/Derrida/ami.htm

El Tiempo. La del plebiscito fue la mayor abstención en 22 años (2 de octubre de 2016). El Tiempo. Recuperado de http://www.eltiempo.com/politica/proceso-de-paz/abstencion-en-el-plebiscito-por-lapaz/16716874

García N. (1989). Culturas híbridas: Estrategias para entrar y salir de la modernidad. México: Grijalbo.

García, N. (1995). Consumidores y ciudadanos. México: Grijalbo.

Hamon, Ph. (1984). Texte et ideologie. París: PUF.

Heidegger, M. (1990). De camino al habla. Barcelona: Ediciones del Serbal-Guitard.

Jácome M. (2009). La novela sicaresca. Testimonio, sensacionalismo y ficción. Medellín: EAFIT.

Jouve, V. (2001). Poétique des valeurs. París: PUF.

Kant, E. (1951). Crítica de la razón práctica. Buenos Aires: Ateneo.

Lakoff, G., y Johnson, M. (1995). Metáforas de la vida cotidiana. Madrid: Cátedra.

McLean, P. (1978). El encuentro de las mentes. Recuperado de http://internacional.elpais.com/ internacional/2016/10/03/actualidad/1475485483_032686.html?id_externo_rsoc=fbads_col_ likes

Mélich, J. C. (2001). La ausencia del testimonio. Barcelona: Ánthropos.

Nietzsche, F. (1967). Obras completas, IV. Madrid: Aguilar.

Nussbaum, M. (1997). Justicia poética. Barcelona: Andrés Bello.

Nussbaum, M. (2001). El cultivo de la humanidad. Barcelona: Andrés Bello.

Platón (1966). Obras completas. Madrid: Aguilar.

Rizzi, A. (3 de octubre de 2016). Muchos 'likes' pocos votos. El País. Recuperado de http:// internacional.elpais.com/internacional/2016/10/03/actualidad/1475485483_032686.html?id_ externo_rsoc=fbads_col_likes

Rorty, R. (1991). Contingencia, ironía y solidaridad. Barcelona: Paidós.

Rorty, R. (2002). Filosofía y futuro. Barcelona: Gedisa.

Rorty, R. (2005). Cuidar la libertad. Madrid: Trotta. 
Rosenblatt, L. (2003). La literatura como exploración. México: FCE.

Sarló, B. (1996). Instantáneas. Buenos Aires: Espasa Calpe.

Serna, J. (2017). El tiempo en zigzag: La crisis de las certezas en el nuevo milenio. Barcelona: Ánthropos. Transparency International (2016). Índice de percepción de la corrupción 2015. Recuperado de

http://transparencia.org.es/wp-content/uploads/2016/01/tabla_sintetica_ipc-2015.pdf

Van Dijk, T. (2003). Ideología y discurso. Barcelona: Ariel, 192.

Vásquez, J. G. (2011). El ruido de las cosas al caer. Bogotá: Alfaguara.

Verón E. (2009). La semiosis social: Fragmentos de una teoría de la discursividad. Barcelona: Gedisa.

Wittgenstein, L. (1988). Investigaciones filosóficas. Barcelona: Crítica.

\section{Abstract}

The commitment to literature for ethical training in the university. A classroom experience with Colombian students

INTRODUCTION. This article aims to show how literature offers a valid alternative to work on citizen values with Higher Education students, making possible the connection of reason with emotion in order to overcome the motivational deficit of the cognitive ethics, which are repeatedly referred by specialists in moral philosophy. The analysis is carried out from a classroom experience within the framework of a research project at a Colombian university. METHOD. The sample is made up of a group of students from both genders of the field of Industrial Technology in their fifth semester at a Colombian university. They were given an open-ended questionnaire at two separate times, before and after the reading of a novel, with the purpose of evaluating the incorporation of ethical and citizen values. RESULTS. The results show that there was a change in the way in which the students expressed their judgments and that a transformation was made in their imaginary regarding the phenomena of drug trafficking, corruption and the Colombian armed conflict. DISCUSSION. From the research, significant achievements are derived for the training in ethical and citizen values in these students and can serve as a basis for future research in the pedagogical field. Literature proves to be an ideal medium to connect reason with emotion and contribute to overcome the motivational deficit in students when the training in ethical and citizen values are undertaken and a historical awareness is sought.

Keywords: Higher education, Literature, Moral sensitization, Citizen values, Historical memory.

\section{Résumé}

Le pari de la littérature pour la formation éthique à l'université. Une expérience dans une classe d'étudiants colombiens

INTRODUCTION. Cet article vise à montrer comment la littérature présente une alternative valable pour travailler les valeurs citoyennes avec les étudiants de l'enseignement supérieure en reliant la pensée et les émotions afin de combler le déficit motivationnel présent dans les étiques cognitives auquel font référence habituellement les spécialistes en philosophie morale. Lanalyse est effectuée à partir d'une expérience dans une classe dans le cadre d'un projet de recherche dans une université colombienne. MÉTHODE. Léchantillon est constitué 
par un groupe d'étudiants des deux sexes en cinquième semestre de technologie industrielle d'une université colombienne auxquels est appliquée, avant et après la lecture d'un roman, un questionnaire de questions ouvertes à deux moments afin d'évaluer l'incorporation des valeurs éthiques et citoyens. RÉSULTATS. Les résultats nous permettent de vérifier un changement dans les jugements de valeurs émis par les étudiants, notant qu'une transformation dans ses imaginaires s'est survenue en ce qui concerne le trafic de drogues, la corruption et le conflit armé en Colombie. DISCUSSION. De cette recherche se dérivent des conclusions importantes pour la formation en valeurs éthiques et citoyens des étudiants universitaires. Celles-ci peuvent servir de base pour des futures recherches dans le domaine de l'éducation. La littérature apparaît comme un moyen permettant de connecter la pensée et les émotions qui contribue à combler le déficit motivationnel chez les étudiants lorsque, d'un coté, leurs formation en valeurs éthiques et citoyens est menée et, d'un autre coté, on encourage une conscience historique.

Mots-clés: Enseignement supérieure, Littérature, Sensibilisation morale, Valeurs citoyens, Mémoire historique.

\section{Perfil profesional de la autora}

\section{Victoria Eugenia Ángel Alzate}

Máster en Literatura por la Universidad Tecnológica de Pereira. Especialista en Didáctica de la Literatura por la Universidad de Caldas. Actualmente adelanta estudios de Doctorado en Literatura. Profesora titular del Departamento de Humanidades de la Universidad Tecnológica de Pereira. Directora del grupo de investigación Lenguaje, Literatura y Política: Estudios transversales. Sus líneas de investigación se centran en la literatura y sus posibilidades pedagógicas y en los estudios culturales. Correo electrónico de contacto: vican@utp.edu.co

Dirección para la correspondencia: Departamento de Humanidades de la Universidad Tecnológica de Pereira, Colombia. Carrera 27 \# 10-02 Barrio Álamos - Risaralda - Colombia. 